\title{
AC 2007-748: IMPROVING TEAM PERFORMANCE IN A CAPSTONE DESIGN COURSE USING THE JIGSAW TECHNIQUE AND ELECTRONIC PEER EVALUATION
}

\author{
Alan Cheville, Oklahoma State University \\ Christine Co, Oklahoma State University \\ Bear Turner, Oklahoma State University
}




\section{Improving Team Performance in a Capstone Design Course using the Jigsaw Technique and Electronic Peer Evaluation}

\section{Introduction}

Most engineering departments use capstone design courses to give student teams the opportunity to design, build, and test a complex project. The advantages of capstone programs are numerous. Such courses expose students to many of the realistic design constraints engineers face. Capstone courses are, in a majority of programs ${ }^{1}$, done by teams of students. Since many capstone courses are industry sponsored, students are able to learn project constraints and budgeting. For these reasons capstone courses are the primary mechanism used by many universities to meet ABET criteria ${ }^{2}$, particularly for outcomes that aren't met in more traditional course formats. Since capstone courses tend to focus on projects which are specific and unique there is no widely accepted model or textbook on which capstone courses are based ${ }^{3}$. The outcomes that can be easily integrated into capstone courses drawn from the a-k outcomes include:

(d) an ability to function on multi-disciplinary teams

(f) an understanding of professional and ethical responsibility

(g) an ability to communicate effectively

(h) the broad education necessary to understand the impact of solutions in a global and societal context

(i) a recognition of the need for, and an ability to engage in life-long learning

(j) a knowledge of contemporary issues

(k) an ability to use the techniques, skills, and modern scientific and technical tools

The electrical engineering department at Oklahoma State University uses a two course capstone design sequence. The first course teaches skills required for design, while the second course has teams tackle open-ended design projects. The paper addresses curricular changes made to the first capstone course which prepare students for teambased design projects in the second course. Specifically we address how to better achieve and document ABET outcome (d), student functioning on multidisciplinary teams. Although ABET requires that students be able to function on "multidisciplinary" teams, the term "multidisciplinary" is left open to interpretation. We have adapted the jigsaw technique, common to elementary and secondary school classrooms ${ }^{4,5}$, to form teams and give each student on the team a unique role and a unique set of skills that permits them to contribute to the team in a meaningful way. We also address ways of improving objective evaluation of student written reports in order to meet ABET outcome (g), "an ability to communicate effectively".

The remainder of this paper presents the results of three curricular changes made to a capstone course in electrical engineering to address these outcomes. The three changes are: setting up a course and team structure that supports the jigsaw technique, implementing peer evaluations that incorporate anonymous feedback to students, and adopting detailed grading rubrics that were made available to students. The changes help to build functional teams, increase participation by "marginalized" students, and results in student artifacts that demonstrate technical communication at a high level. 


\section{A Capstone Jigsaw Course Structure}

The jigsaw technique implemented in the capstone course builds on principles of cooperative learning and defines "multidisciplinary" as providing students a unique role (discipline) on a team. To accomplish this we organize capstone teams on a jigsaw model. The adapted jigsaw technique provides each student an explicit role by training students in electronic design or fabrication skills then setting up teams to utilize these skills. The organization and structure of the jigsaw technique is discussed along with the difficulties encountered.

The jigsaw technique is a collaborative teaching technique which was originally designed to help younger students learn information by taking on multiple roles. Students get to become the teacher, listen to others with information they lack, perform an essential part of the solution, and function on a team by creating a deliverable that requires the students to work together and share their knowledge with each other ${ }^{4,5}$. The technique requires that the students are divided up into small groups of three to six students depending on how many assignments or sections the faculty comes up with. This first group is considered the "expert" group because the students will work on one part of a project or single assignment and research that topic. After learning about their part, the students are divided into new mixed groups such that each new team has at least one member of the previous teams on it. In these reformed teams students share the information learned in their first group with the other members in that group. For example, a class of sixteen students is divided into four teams of four. Each team of four is taught some unique piece of information (i.e. a piece of the puzzle) that will aid in the overall solution. The teams are then reassigned into new groups. Each new group has one member from each of the four previous teams. These newly formed teams should now be able to solve the given task since every team has each piece of the puzzle; hence the name "jigsaw" referring to a jigsaw puzzle. This teaching style allows the students to take the role of a student in their first group and a teacher in the second group. The technique also helps marginalized students to take a more active role in the course. Students who are low performers in the first group have unique knowledge or skills to contribute to the success of the second group.

To achieve the outcome of working on multidisciplinary teams, the first of two capstone courses adapts the jigsaw technique to allow students to work on multidisciplinary teams. The term "multidisciplinary" in this context means that the students learn a skill or discipline before they begin working on teams in which they will need those skills for projects. To implement the jigsaw technique in the capstone course, the course is first divided into three major phases that are completed consecutively. In each phase teams complete a design project. All phases have different goals but share some common features. All the phases are carried out independently by students who are supported by ninety minutes per week of active learning instruction in the classroom. A group of teaching assistants hold regular office hours to aid the students with any large problems. Each team is allotted two hours of consulting time per project to ask the teaching assistants for help. The use of consulting time provides help to students on any issue, but 
lets students know that such aid is limited. The consulting time has the effect that students work with each other more and seek other sources of information instead of asking the teaching assistant simple questions; more difficult questions are still brought to the TA. For all phases teams create a written proposal outlining the details of their project and how the method of solution they will employ. The proposals are resubmitted until a passing score of at least a ninety percent is obtained. Proposals must receive a score of $90 \%$ before the team is allowed to continue with any other part of the project. At the conclusion of each phase teams submit a written technical report. The team written report requires a high level of technical detail about how the project was accomplished, problems encountered and their solutions, what the project does, how is it used, etc. Both proposal and project reports are graded using a rubric by a team of the instructors and teaching assistants. This will be discussed in more detail later.

To implement the jigsaw technique, teams are reorganized after each phase of the course. Generally team performance improves with time and better performance is obtained when teams are not reorganized ${ }^{6}$. Using the jigsaw technique, however, requires team reorganization. In the first phase of the course the students were organized into teams based on two criteria. The first was overall grade point average and the second was the area of specialization within electrical engineering each student pursued. The goal was to create teams diverse both in overall academic ability as well as ensure teams had the skills needed to solve the design problem that was posed to them. Although our evaluations show that GPA is, at best, weakly correlated with success in this pre-capstone course we have little information on students at the start of the semester. We first set up the design teams for the second project to ensure the main design work will have students with necessary academic skills. After the second teams are set up we work backwards to set up the teams for the first project.

The first project creates the "expert" groups of the jigsaw technique in two steps. The first step is for students to become certified in an area of electronic fabrication, design, or testing by acquiring a set of practical skills. The second step is for the class as a whole to fabricate an electronic system. The student teams role-play different divisions at an electronic fabrication company. A preliminary schematic diagram and design of a case or mounting system is submitted by a customer who would like a prototype of the circuit to be built. Students work as a team to learn a certain skill (discipline) in either electronic design or fabrication. Students are divided up into six small groups of roughly three or five members (depending on class size), and each team specializes in one of the following disciplines:

- Simulation: The simulation team is responsible for designing and testing the schematic using ORCAD or other schematic software.

- CAD: The CAD team takes the schematic designed by the simulation team and creates a layout of the printed circuit board (PCB) using a layout design software. - PCB Fabrication: The printed circuit board fabrication team is responsible for taking the electronic layout created by the CAD team and mills out the design to create a circuit board 
- Electronic Assembly - The electronic assembly team is responsible for soldering and mounting all of the parts onto the PCB that was made by the PCB fabrication team.

- Case Fabrication - The case fabrication team is responsible for creating and shaping a case for the PCB.

- Testing and Measurements - The testing and measurements team is responsible for insuring that the system works and functions as needed.

Students are first provided a set of reading material and other learning resources for the skill in question. After reading the material they individually take an on-line quiz to test their knowledge of the material. Once the quiz is passed the team or small groups of students are taught one of the skills mentioned early by an expert (teaching assistant) then given a small project to complete independently which is then evaluated by the expert using a rubric. If the student passes inspection then the student becomes certified in that area of skill.

In the second step student teams use the acquired skills to contribute to the first project. The class acts as one large team trying to create a project which is created one step at a time as described previously. Each team completes their part of the project then passes information or products to the team(s) that are in charge of the next fabrication steps as shown in Figure 1.

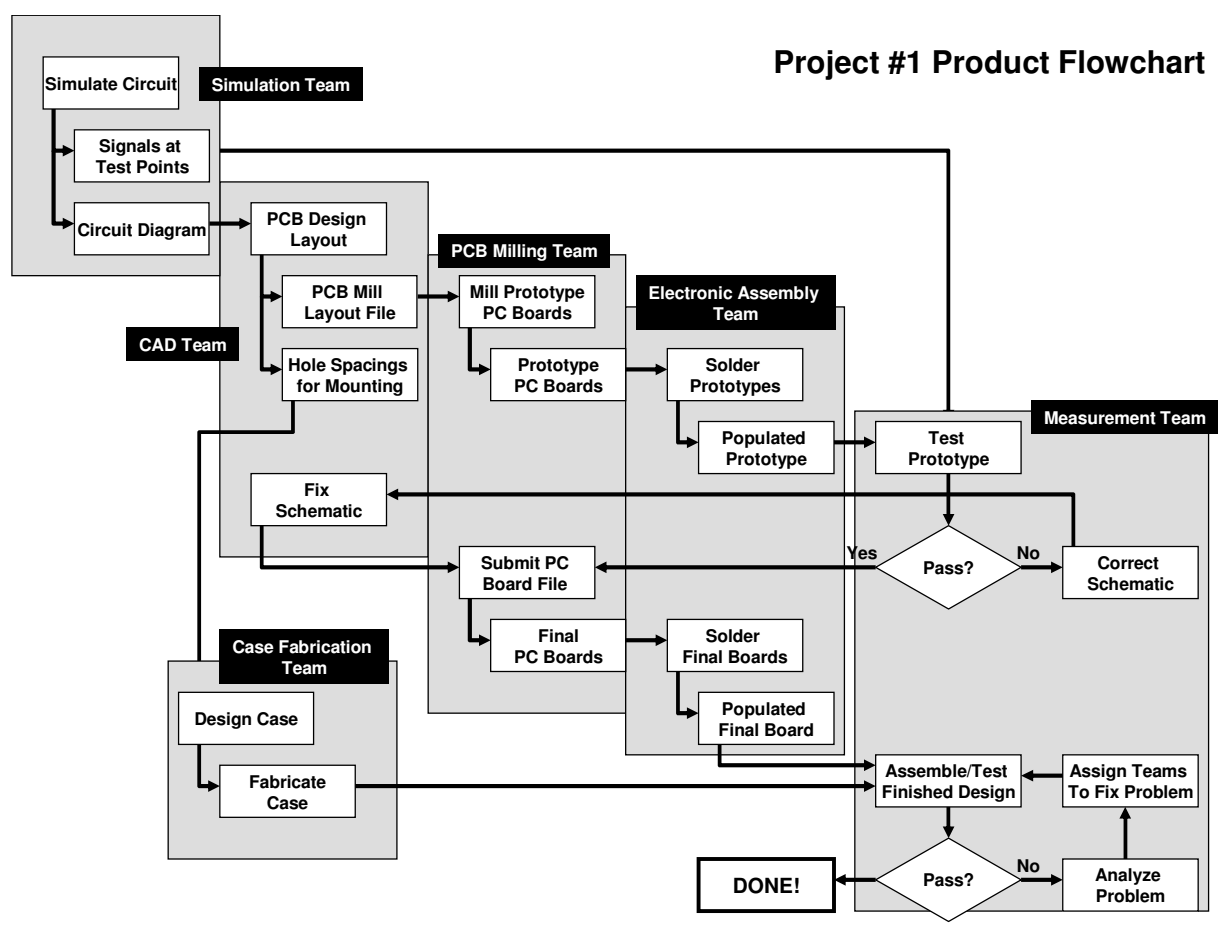

Figure 1: A general organizational flowchart for the first project that is given to students.

The results of this first project have been mixed. On the positive side students report that the design, fabrication, or testing skills are extremely valuable and help them succeed in design courses. We have observed a high level of transfer of these skills to later projects. 
The projects are generally successful and exhibit a high level of quality. Almost all students are engaged in the project.

There are, however, several disadvantages to this approach. The organization of this project is complex with a high level of coordination required between students, TA's, and instructors. Since coordination is done by TA's and the instructor the time burden is extremely high. Another disadvantage of this approach is that there are periods where teams are extremely busy while at other times students have little work to complete. For some students scheduling conflicts with other classes can lead to task overload. Feedback from students indicates they value the training in fabrication skills. Students see the tightly imposed deadlines as realistic, but feel that they could have learned more if they had had more time to complete the projects. Another area that could be improved is how to assign students to teams to ensure that all skills are equally represented. Since most student prefer fabrication skills which are not taught in previous courses, some students feel they would have had a more valuable experience on a different team. We are changing the format of the first project and will report pre-post changes to learning outcomes in a future publication.

For the second phase of the pre-capstone course new teams are organized using the jigsaw technique so that each team has members who are experts in the set of skills needed to complete the design project. The jigsaw technique gives each student an opportunity to apply their skills to the design, fabrication, and testing of an electronic system. The students are rearranged into new groups so that each team has at least one "expert" in every discipline as shown in Figure 2. In the second phase each team is responsible for a different subsystem of a larger electronic system. The larger system forms the class project. To build on the expectations of quality taught in the first project and allow teams to use the skills they acquired, this phase requires that each team's subsystem be built on a printed circuit board and be functionally complete and working by the end of the project.

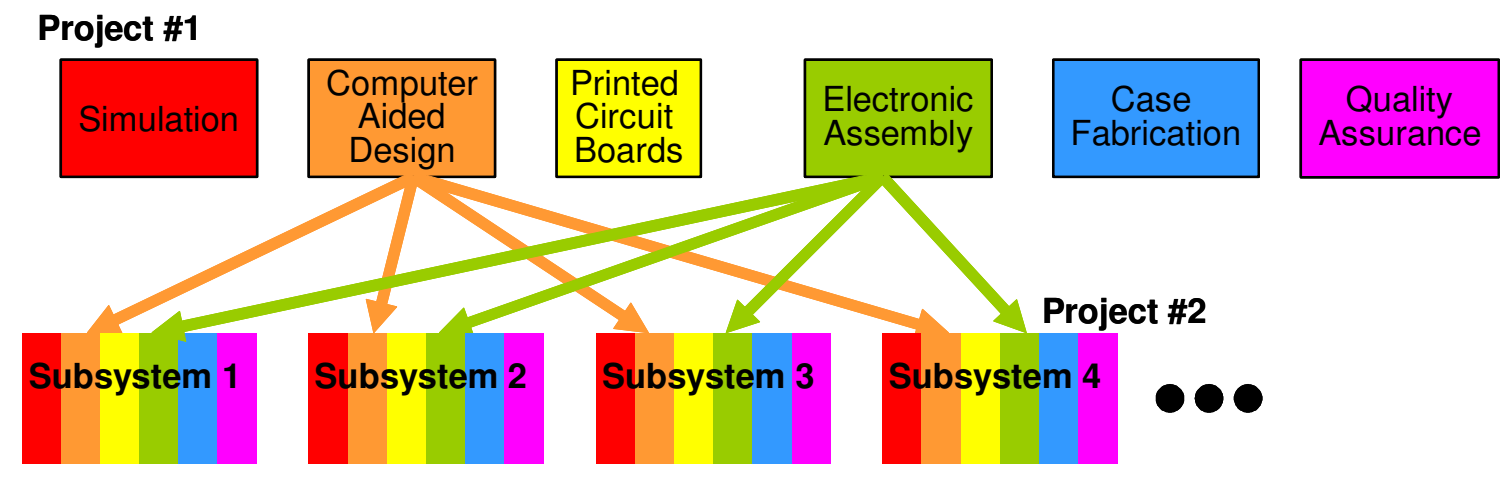

Figure 2: Block diagram explaining the rearranging of teams from project one to project two.

Students are not required to teach each other their disciplines as in the traditional jigsaw approach. Instead each student is expected to take on responsibilities associated with their skill for the team. Since each student has a skill to contribute to the project, even 
marginal students are able to contribute to project outcomes if they choose to. In the second project the students work together on the new multidisciplinary teams to create a unique component of subsystem of a larger, more complex system. Each team becomes an expert on their subsystem, as do individual students who are involved in the design process. In this way the mixed teams now become "expert" teams on their subsystems. Unlike the first project students must take initiative to become experts on their subsystems, expertise is not assured by the structure of the course. Student participation, however, is evaluated through electronic peer evaluation discussed later and encourages all students to contribute to team efforts.

The deliverable of the second phase is a set of $\mathrm{N}$ working subsystem from each team where $\mathrm{N}$ is the number of teams to be created in the third phase of the project. The subsystems from each team will be integrated into a larger system in the third phase of the course. Using the jigsaw method the teams are rearranged again such that each new team has at least one "expert" of the subsystem design as shown in Figure 3. The new mixed (multidisciplinary) are required construct working products of the complex system. In an ideal world this would simply require plugging the connectors of one system into another and providing power. In reality most system are not built to the specifications required and a significant amount of additional work is required to complete the system. This ideally requires that the "expert" on each of the teams help in the integration process. In practice not all students have reached expert status on their subsystems during the second project and there is a lot of inter-team interaction.

\section{Project \#2}

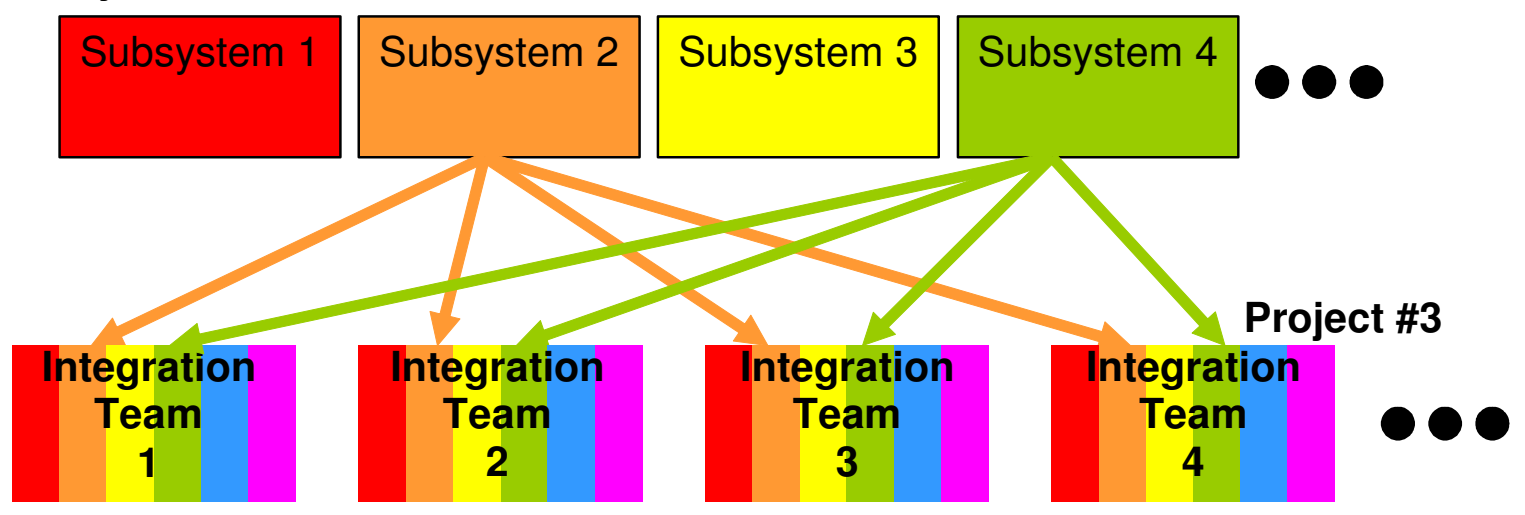

Figure 3: Block diagram explaining how individuals on teams are rearranged from project two to project three to implement the jigsaw technique.

To summarize, this course uses the jigsaw technique twice to reform teams. The first jigsaw method is used in first and second phases of the course and the second jigsaw technique is used during the second and third phases. In the first phase students are taught a single skill or discipline. The students are "jigsawed" into new groups in the second phase so that each new team has a complete group of fabrication skills. These groups then use their skills from the first phase to solve an open ended design problem, creating a subsystem of a larger class project. After completion of the second phase 
when students have become expert in their team's subsystem they are again "jigsawed" for the third phase. Here, each new team has at least one subsystem "expert" from the phase two teams. These teams then combine each of the subsystems together to create a single system.

There are several difficulties that can occur when using this technique. Students that do not fully participate on their team and lack knowledge will hurt their team on the next project. Such marginalized students lack the knowledge or skills to complete their portions of the project. To help address this issue several active learning modules in the classroom portion of the course focus on the concept of quality and give example of ineffective teams. Another issue is time conflicts in the first project. Students who do not begin a task early can find themselves with only two to three days to accomplish their task and then pass it on to the next team. This problem is exacerbated if flaws are found in the design. There are quality control and feedback loops built into the fabrication process shown in Figure 1. To help solve these scheduling problems a weekly timeline for the first project was created for students and described to them on the first day of class. This is shown below in Figure 4. Another problem that can occur in all of the projects is teams that miss deadlines or do not start work until just before the deadline. Several time management techniques have been taught in class to address this issue.

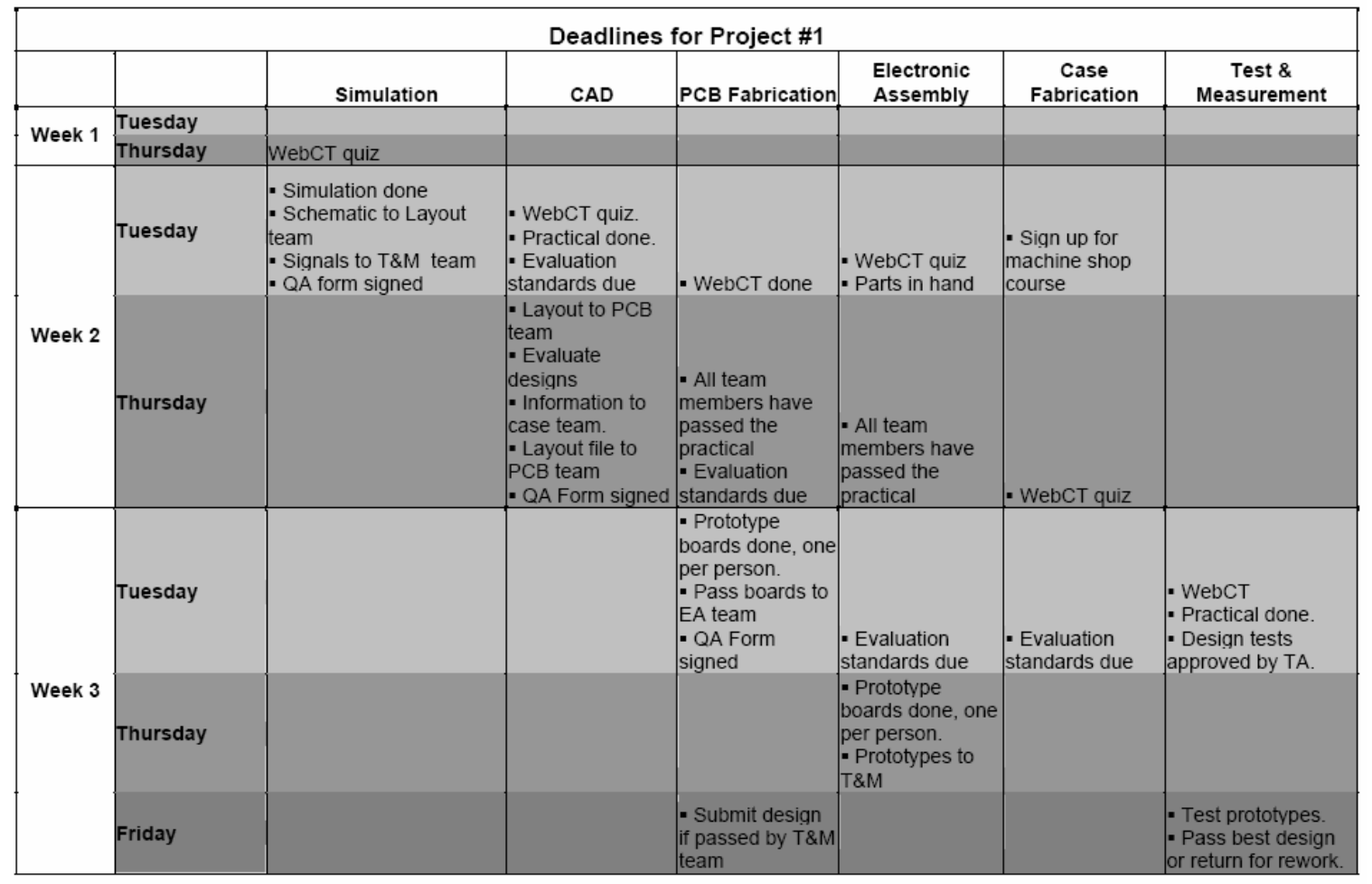

Figure 4: Timeline for project one showing the deadlines for each team (columns) and what is due and when (rows) 


\section{Assessing Teams Through Peer Evaluations}

An online, electric peer-evaluation system was implemented to help increase student accountability. This on-line system permits anonymous feedback from students and is currently undergoing validation tests. The peer evaluation system is configured by the faculty member in charge of the class. The system is fully customizable and the instructor can choose to include a variety of evaluation modules. Currently the system is set up with four different evaluation modules. One module assesses team member attitude and value to the team (Likert scale). A second module has peers report the effort put forth by team members on team tasks (as a percentage of total effort). The final two modules have peer's rate each student's overall value to the team (numeric rating) and asks students to provide open-ended, written, anonymous feedback to team members. The text of questions, instructions, and the type of feedback can be customized on this system.

Teams fill out peer evaluations at the end of each of the three projects. Each student logs onto the peer evaluation website and is guided through each of the sections that contain questions pertaining to his or her teammates' performance on the project. For the first section of the peer evaluation, the student is asked to rank their team members on a scale of 1 to 5 , where a value of 5 suggests that the team member was exceptional and performed better than expected and a value of 1 suggests that the team member performed below expectations. A value rating of 3 suggests that the team member met the evaluator's expectations. The value rating questionnaire is shown in Figure 5.

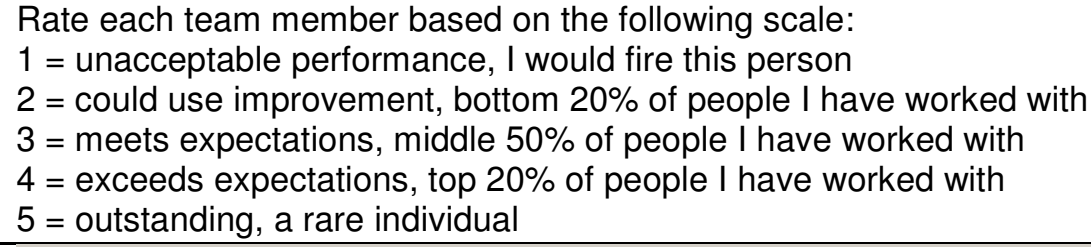

\begin{tabular}{|l||}
\hline $\begin{array}{l}\text { Reliable: This person attended meetings, showed up for work } \\
\text { sessions, and was generally dependable. I can count on this } \\
\text { person to get the job done. }\end{array}$ \\
\hline $\begin{array}{l}\text { Responsible: This persons took on a fair share of the work and } \\
\text { did not make excuses for poor performance. They were } \\
\text { responsible for their actions. }\end{array}$ \\
\hline $\begin{array}{l}\text { Qualified: This person had the ability do accomplish the tasks } \\
\text { they took on. Their work was of high quality, and their opinions } \\
\text { were valuable. }\end{array}$ \\
\hline $\begin{array}{l}\text { Positive Attitude: This person's attitude and work ethic helped } \\
\text { make this a more enjoyable experience. They offered } \\
\text { constructive criticism and were willing to work with team } \\
\text { members if they needed help. They did not get defensive. }\end{array}$ \\
\hline
\end{tabular}

Figure 5: The format of questions on the attitude peer evaluation system. In the actual system, "Peer 1" through "Peer 3" have the names of teammates. 
The second section is a simple table of tasks in each column with team member names listed along rows. The sum of all columns must add to $100 \%$ corresponding to the total work done by all members of the team. The system reports the sum of rows to faculty to they can evaluate efforts of team members. This section of the evaluation is shown in Figure 6. On the third section of the peer evaluation, the student determines a quantitative value for each team member's effort towards the project. Ideally, each student would contribute equally and an effort of $100 \%$ would suggest that the student contributed a fair amount of work.

Please provide the percentage of work each person contributed to each of the tasks listed below. All columns must add to $100 \%$ ! If all team members contributed equally, put the same percentage in each column, i.e. $25 \%$ for a four person team, $20 \%$ for a five person team, etc. If one of the listed tasks does not apply to your team, simply put $0 \%$ in that column.

Generally a well functioning team will have different team members be responsible for different tasks and the values below should reflect this distribution of effort. In this section of the evaluation you are asked to assign the relative percentage of work done by all member on the team, including yourself. Each column represents part of the team grade for the class and each column should add up to $100 \%$. If any column does not add up to $100 \%$ when you click the submit button, your scores will not be accepted, and you will have to return and correct the values. Use integer numbers only or you may have to start from the beginning!

The numbers you enter here will be used to calculate a suggested rating for each of your team members. You do not need to use the number suggested, but should your rating differ greatly from the values you enter, you may be asked to justify them to the instructor or TA.

\begin{tabular}{|c|c|c|c|}
\hline & $\begin{array}{l}\text { Working on the team. Being a } \\
\text { good team member. Shows up } \\
\text { to meetings on time, contributes } \\
\text { their fair share of the work, has a } \\
\text { positive attitude }\end{array}$ & $\begin{array}{l}\text { Helping the team pass } \\
\text { the quizzes, studied } \\
\text { hard, made good } \\
\text { suggestions. }\end{array}$ & $\begin{array}{l}\text { Contributing to the final } \\
\text { report. Completed their } \\
\text { section, helped with editing, } \\
\text { did their work on time with } \\
\text { good quality. }\end{array}$ \\
\hline $\begin{array}{l}\text { Peer } \\
1\end{array}$ & & & \\
\hline $\begin{array}{l}\text { Peer } \\
2\end{array}$ & & & \\
\hline \begin{tabular}{|l} 
Peer \\
3
\end{tabular} & & & \\
\hline $\begin{array}{l}\text { Peer } \\
4\end{array}$ & & & \\
\hline
\end{tabular}

Figure 6: The metric used for students to evaluate teammate's effort on projects.

Based on the numerical values from the first and second section, a suggested peer evaluation score is provided by the peer evaluation software. The suggested score is calculated by the system using an algorithm set up by the instructor, who can also choose not to display suggested scores. The student then enters a value either based on the suggested score or on their own assessment of their teammates performance. In the capstone design course this score is then factored into the final project grade. For 
example, if Sue gave Bob a peer evaluation score of $82 \%$ and the final project grade was a $96 \%$, then Bob's project grade would be $0.82 * 0.96$ or $78.7 \%$. At the end of a project students are able to see their overall team rating and comments, but individual responses are anonymous. While completing the peer evaluation the student must consider the work done by each student based on what was established on the team contract. The format for the overall evaluation is shown in Figure 7, below.

A score of $100 \%$ represents an average team member who did all the work expected of them. Scores below $100 \%$ reflect team members who contributed less than their fair share of effort, while scores over $100 \%$ are for team members who contributed more than their share.

You have a maximum of 100 points to assign per person on your team other than yourself. The total points you can assign is then $100^{*}(\mathrm{~N}-1)$ where $\mathrm{N}$ is the number of people on your team. You do not have to use all of your points if you feel some team members did not put in $100 \%$ of their share of the work on this project. You will not provide a rating for yourself. You have: $\mathbf{3 0 0}$ points to assign to your teammates.

Team Member Overall Rating Value Rating Effort Rating Suggested Score

\begin{tabular}{|c|c|c|}
\hline Peer 1 & 40.00 & 60.00 \\
\hline Peer 2 & 40.00 & 60.00 \\
\hline Peer 3 & 40.00 & 60.00 \\
\hline
\end{tabular}

Figure 7: Format of the evaluation section used to evaluate each team member's overall performance

Overall the students that perform well one module of the peer evaluation do well in all modules. The data shown in the table below indicates correlation values and $\mathrm{p}$-values for a single semester course consisting of seventeen students. The values show a high and statistically significant correlation coefficient between the three sections of the evaluation tool. This data indicates that students who are scored highly by peers well on one section of the peer evaluation are also scored highly on other sections.

\begin{tabular}{|l|c|c|c|}
\hline & [A] & [B] & [C] \\
\hline [A] Peer: Attitude & \multicolumn{1}{|c|}{} & \\
\hline [B] Peer: Effort & $0.78(\mathrm{p}<.005)$ & \\
\hline [C] Peer: Overall & $0.86(\mathrm{p}<.005)$ & $0.86(\mathrm{p}<.005)$ & \\
\hline
\end{tabular}

Table 1: Correlation coefficients for the three areas of the peer evaluation score for $\mathrm{N}=17$ students.

Typically in the first project students do not take peer evaluation seriously. Students feel it is difficult to grade down peers who do not perform well. This is partly due to the fact that peer evaluations are directly used to scale grades. However as the course progresses and students are given more individual responsibility for completing projects the students became more adept at peer evaluation. Figure 8 shows the mean and standard deviation for the overall scores of the three peer evaluations done in the three phases of the course. While the mean stays around one hundred, the deviation increases from one evaluation to the next. We interpret the increase in standard deviation as students becoming more 
discerning about their team members. The variation of scores reported for the effort and value ratings of the peer evaluation instrument increased as well. Comments reported by students on the peer evaluation support this view.

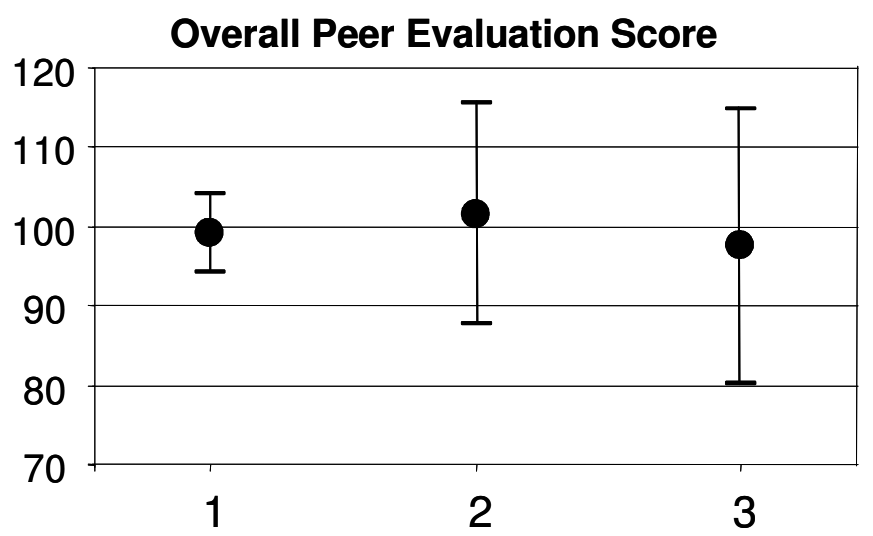

Figure 8: The mean value $(\bullet)$ and standard deviation of the overall section of the three peer evaluations taken during the course.

\section{Adoption of Grading Rubrics}

The final change made to the course was the adoption of grading rubrics that were given to students. This was done to better clarify expectations on written reports. Since each project had a proposal and a final project reports two different grading rubrics were created. Although the rubrics differ slightly between projects, the overall structure and grading scale of the rubrics is constant throughout the course so that students are not exposed to changing expectations. Figure 9 shows the grading scale that is used for both proposal and project reports, while Figure 10 shows the grading rubrics for the technical final project report. Note that while it would be possible to create more detailed rubrics, these would have to be adapted continuously as projects in the course changed, and for different projects within the course.

One of the purposes of rubrics was to help assure that report grades were as objective as possible rather than subjective and based who graded the report. Such objective evaluation is critical if reports are to be used for evaluating changes in student learning or ABET accreditation. To help ensure subjective evaluation team's reports were graded using a panel consisting of the course instructor and teaching assistants. For each report submitted by student teams, there is one main grader and two secondary graders. Similar to NSF proposal reviews one primary reviewer is assigned as well as a two secondary reviewers. The primary reviewer is responsible for returning feedback to the team. The grading panel undergoes calibration sessions at the start of each semester. In assigning scores the panel discusses scores and reaches a consensus rather than averaging reviewer scores. Although this is time consuming for the first few reports, once the panel becomes calibrated the grading process goes extremely rapidly and significantly reduces the grading burden on any individual. It also results in timelier grading since there are clear divisions of responsibility. 


\begin{tabular}{|c|c|c|}
\hline Rating & Points Awarded & Description of Judging Criteria \\
\hline Excellent & $100 \%$ & $\begin{array}{l}\text { - Realizes points 1-6 fully and completely. } \\
\text { - Demonstrates originality and creativity. } \\
\text { - } \quad \text { Fits in well with, and is supported by, the rest of the document }\end{array}$ \\
\hline Very Good & $90 \%$ & $\begin{array}{l}\text { - } \quad \text { Realizes points 1-6 fully and completely. } \\
\text { - } \quad \text { Demonstrates competence, but not originality and/or creativity. } \\
\text { - }\end{array}$ \\
\hline Good & $80 \%$ & $\begin{array}{l}\text { - Realizes points 1-6 adequately. } \\
\text { - } \quad \text { Demonstrates competence with a few minor errors. } \\
\text { - Section has minor inconsistencies with the rest of the document }\end{array}$ \\
\hline Fair & $70 \%$ & $\begin{array}{l}\text { - Realizes most of points 1-6 adequately. } \\
\text { - } \quad \text { Demonstrates few major errors. } \\
\text { - Section has serious inconsistencies with the rest of the document }\end{array}$ \\
\hline Poor & $60 \%$ & $\begin{array}{l}\text { - Does not realize some points } 1-6 \text { or does so poorly. } \\
\text { - } \quad \text { Demonstrates few major errors. } \\
\text { - Section has serious inconsistencies with the rest of the document }\end{array}$ \\
\hline Unacceptable & $0 \%$ & $\begin{array}{l}\text { - } \quad \text { Completely misses at least two of points } 1-6 \text {. } \\
\text { - } \quad \text { Demonstrates a significant number of major errors. } \\
\text { - Section has serious inconsistencies with the rest of the document }\end{array}$ \\
\hline
\end{tabular}

Figure 9: General grading scale used for rubrics for both proposals and final reports.

\begin{tabular}{|c|c|c|c|c|c|c|c|}
\hline Section & Summary & $\begin{array}{l}\text { Scope } \\
\text { of Work }\end{array}$ & $\begin{array}{l}\text { Technical } \\
\text { Description }\end{array}$ & $\begin{array}{l}\text { Performance } \\
\text { Characterization }\end{array}$ & $\begin{array}{l}\text { Summary } \\
\text { \& Future } \\
\text { Work }\end{array}$ & Specifications & References \\
\hline Section Points & 5 & 10 & 15 & 25 & 10 & 25 & 10 \\
\hline \multicolumn{8}{|l|}{$\begin{array}{l}\text { The section is technically } \\
\text { correct in all aspects. }\end{array}$} \\
\hline \multicolumn{8}{|l|}{$\begin{array}{l}\text { Covers all the criteria listed } \\
\text { for the section in detail. }\end{array}$} \\
\hline \multicolumn{8}{|l|}{$\begin{array}{l}\text { Writing is clear, concise, and } \\
\text { directed towards and meets } \\
\text { the needs of a technical } \\
\text { audience. }\end{array}$} \\
\hline \multicolumn{8}{|l|}{$\begin{array}{l}\text { Writing is clear, concise, and } \\
\text { directed towards and meets } \\
\text { the needs of a technical } \\
\text { audience. } \\
\text { Provides supporting } \\
\text { arguments, evidence, } \\
\text { examples, and details. }\end{array}$} \\
\hline \multicolumn{8}{|l|}{$\begin{array}{l}\text { All figures are labeled, and } \\
\text { clearly express the results of } \\
\text { experiments or calculations. }\end{array}$} \\
\hline \multicolumn{8}{|l|}{$\begin{array}{l}\text { Section is well organized and } \\
\text { uniform with a consistent } \\
\text { level of excellence }\end{array}$} \\
\hline Rating & & & & & & & \\
\hline
\end{tabular}

Figure 10: The grading rubric for the final report. For each of the

In order to help teach professional expectations for technical communication teams are allowed to submit the final technical document before the deadline for a "pre grade". The graded paper (by the main reviewer only) is returned to the team within 72 hours. Teams may modify and resubmit papers up to the submission deadline. This has been extremely successful both to help teach elements of technical communication and to clarify expectations among students. Most teams submit draft documents for a pre-grade to receive guidance on their approach and the level of detail required.

\section{Summary and Impact on Practice}


In conclusion, the use of the jigsaw technique for teaching this class has been beneficial in helping to prepare students for the second capstone design course. While the jigsaw technique can be difficult to implement for technical projects it does help inclusion of marginalized students, particularly in the first and second projects. The technique is less effective in moving from the second to the third project when expectations are less clear and students are given less structured projects. The jigsaw technique is most effective in giving students design and fabrication skills. We have observed that these skills have a high rate transfer to subsequent projects. Fabrication skills are also seen to transfer to the second capstone design course where team makeup is partially determined by the skills each student brings. A list of student skills is given to the instructor of the second design course each semester. We observe the same students we trained taking on those fabrication roles in the second design course and using the same techniques for fabrication they were trained in.

The use of a formal and repeatable method of peer evaluation has been a great improvement for holding students accountable for their work. The system provides an easy way to keep track of who is doing what on the projects and student progress can be monitored easily by the instructor. The system also allows for teammates to comment on each other's performance. Overall peer evaluation scores (the mean of the three overall scores) are one of the criteria used to set up teams in the second capstone course. The faculty member teaching that course does not put two low-performing students on the same team. While there is not solid data on team performance in the second capstone course due to a lack of objective evaluation standards, faculty report a smaller fraction of problematic teams after this policy was implemented.

Finally, the addition of the grading rubrics, resubmission of papers, and using a trained panel of graders has improved the quality and objectiveness of technical writing and written student artifacts. The subjectiveness of written evaluations is one of the main difficulties reported in assessing capstone courses ${ }^{7}$, and the techniques implemented provide more subjective grading as determined by the agreement of scores of trained evaluators.

The authors acknowledge support from the National Science Foundation through award NSF0530588. Ms. Co and Mr. Turner would like to acknowledge support from a National Science Foundation REU award (NSF0631565) which enabled them to conduct the research presented in this paper. Any opinions, findings and conclusions or recommendations expressed in this material are those of the authors and do not necessarily reflect the views of the National Science Foundation.

\section{Bibliography}

[1] S. Howe and J. Wilbarger, "2005 NATIONAL SURVEY OF ENGINEERING CAPSTONE DESIGN COURSES," presented at ASEE Annual Meeting, Chicago, 2006.

[2] "Criteria for Accrediting Engineering Programs, 2006-2007," Accreditation Board for Engineering and Technology, Baltimore, MD 2006. 
[3] D. G. Meyer, "Capstone Design Outcome Assessment: Instruments for Quantitative Evaluation," presented at Frontiers in Education, Indianapolis, 2005.

[4] E. Aronson, N. Blaney, C. Stephan, J. Sikes, and M. Snapp, The Jigsaw Classroom. Beverly Hills, CA: Sage, 1978.

[5] J. G. Greeno, A. M. Collins, and L. B. Resnick, "Cognition and Learning," in Handbook of Educational Psychology, D. C. Berliner and R. C. Calfee, Eds. New York: Simon \& Schuster Macmillan, 1996, pp. 15-46.

[6] S. G. Adams, "Building Successful Student Teams in the Engineering Classroom," Journal of STEM Education, vol. 4, pp. 27-32, 2003.

[7] L. J. McKenzie, M. S. Trevisan, D. C. Davis, and S. W. Beyerlein, "Capstone Design Courses and Assessment: A National Study," presented at ASEE Annual Conference and Exhibition, 2004. 